\title{
Sometimes an ounce of extracorporeal membrane oxygenation prevention is worth a pound of extracorporeal membrane oxygenation cure
}

\author{
Pankaj Saxena, FRACS, PhD, ${ }^{a}$ Randall Flick, MD, ${ }^{b}$ and Kevin L. Greason, MD, ${ }^{a}$ Rochester, Minn
}

Emergency aortic valve replacement in the setting of severe aortic valve stenosis and cardiogenic shock carries increased risk of morbidity, including postcardiotomy cardiac failure. ${ }^{1}$ Mechanical circulatory support with extracorporeal membrane oxygenation (ECMO) can be a lifesaving therapy for such patients. We report here the management of a patient with severe prosthetic aortic stenosis in cardiogenic shock whom we treated with ECMO therapy to achieve clinical stabilization before urgent aortic valve replacement.

\section{CLINICAL SUMMARY}

A 77-year old woman was admitted with a non-STsegment myocardial infarction, severe prosthetic aortic valve stenosis, and an ejection fraction of $37 \%$. The patient had cardiogenic shock develop and underwent placement of an intra-aortic balloon pump. This resulted in stabilization of her systemic blood pressure; however, acute kidney injury developed, with low urinary output $(67 \mathrm{~mL}$ over 6 hours) and elevated serum creatinine level (acute increase from 1.6 to $2.2 \mathrm{mg} / \mathrm{dL}$ ).

The patient was taken to the operating room for emergency reoperative aortic valve replacement. On induction of anesthesia, systemic systolic arterial hypotension $(83 \mathrm{~mm} \mathrm{Hg})$ and pulmonary systolic arterial hypertension $(71 \mathrm{~mm} \mathrm{Hg})$ developed. The patient required frequent intravenous boluses of epinephrine to maintain perfusion, and we did not believe that she would survive long enough to allow the planned reoperative aortic valve replacement.

We decided to proceed with ECMO therapy. Arterial cannulation was performed with a 10-mm Gelsoft graft (Terumo Cardiovascular Systems Corporation, Ann Arbor, Mich) sutured as a chimney graft to the right axillary artery. A Bio-Medicus venous cannula (Medtronic Bio-Medicus, Inc, Eden Prairie, Minn) was placed through the right femoral vein. ECMO therapy immediately stabilized the

\footnotetext{
From the Divisions of Cardiovascular Surgery, ${ }^{\mathrm{a}}$ and Anesthesiology, ${ }^{\mathrm{b}}$ Mayo Clinic, Rochester, Minn.

Disclosures: Authors have nothing to disclose with regard to commercial support.

Received for publication Aug 9, 2013; accepted for publication Aug 29, 2013; available ahead of print Oct 29, 2013.

Address for reprints: Kevin L. Greason, MD, Division of Cardiovascular Surgery, Joseph 5-200, Mayo Clinic, 200 First St SW, Rochester, MN 55905 (E-mail: greason.kevin@mayo.edu).

J Thorac Cardiovasc Surg 2014;147:1102-3

0022-5223/\$36.00

Copyright (c) 2014 by The American Association for Thoracic Surgery

http://dx.doi.org/10.1016/j.jtcvs.2013.08.084
}

patient's hemodynamics. She had dramatic clinical improvement, with normalization of the systemic systolic arterial blood pressure $(128 \mathrm{~mm} \mathrm{Hg})$, pulmonary systolic arterial pressure $(39 \mathrm{~mm} \mathrm{Hg})$, urinary output $(3265 \mathrm{~mL}$ over 24 hours), serum creatinine level $(1.3 \mathrm{mg} / \mathrm{dL})$, and chest radiographic appearance (Figure 1, $A$ and $B$ ).

The patient was returned to the operating room 36 hours later to undergo reoperative aortic valve replacement. This operation included institution of cardiopulmonary bypass though the ECMO cannulas, resternotomy, myocardial protection with antegrade and retrograde cardioplegia, aortic root enlargement, and aortic valve replacement with a 21-mm Carpentier Edwards Perimount valve (Edwards Lifesciences, Irvine, Calif). The patient was separated from cardiopulmonary bypass without difficulty.

The postoperative course was marked by continuous improvement. The intra-aortic balloon pump was removed on postoperative day 2 , and the patient was extubated on day 4. Renal function remained stable (creatinine level, $1.5 \mathrm{mg} / \mathrm{dL}$ ). Discharge echocardiography showed a normally functioning prosthetic aortic valve. The patient was discharged home on day 13 with New York Heart Association class I function (Figure 1, C).

\section{DISCUSSION}

Clinical management of severe prosthetic aortic valve stenosis with cardiogenic shock poses a formidable challenge. Emergency operative intervention in this setting is associated with an increased risk of mortality, as noted by O'Brien and colleagues, ${ }^{2}$ who reported a mortality odds ratio of 3.77 (95\% confidence interval, 2.75-5.16) in this group of patients.

Preoperative ECMO therapy in our patient resulted in restoration of cardiac output with improvement in organ function. Other treatment options included proceeding with a balloon aortic valvuloplasty or transcatheter aortic valve replacement. ${ }^{3,4}$ We decided against these because of (1) potential acute aortic regurgitation as the result of rupture of a bioprosthetic valve cusp, (2) nonapproved transcatheter technique, and (3) clinical improvement with ECMO therapy.

The role of preoperative ECMO therapy in patients such as ours is not well established. Larger studies are needed to define the role of ECMO therapy in acutely sick patients with aortic valve disease. The idiom, "an ounce of prevention is worth a pound of cure," may have application to this group of patients. 

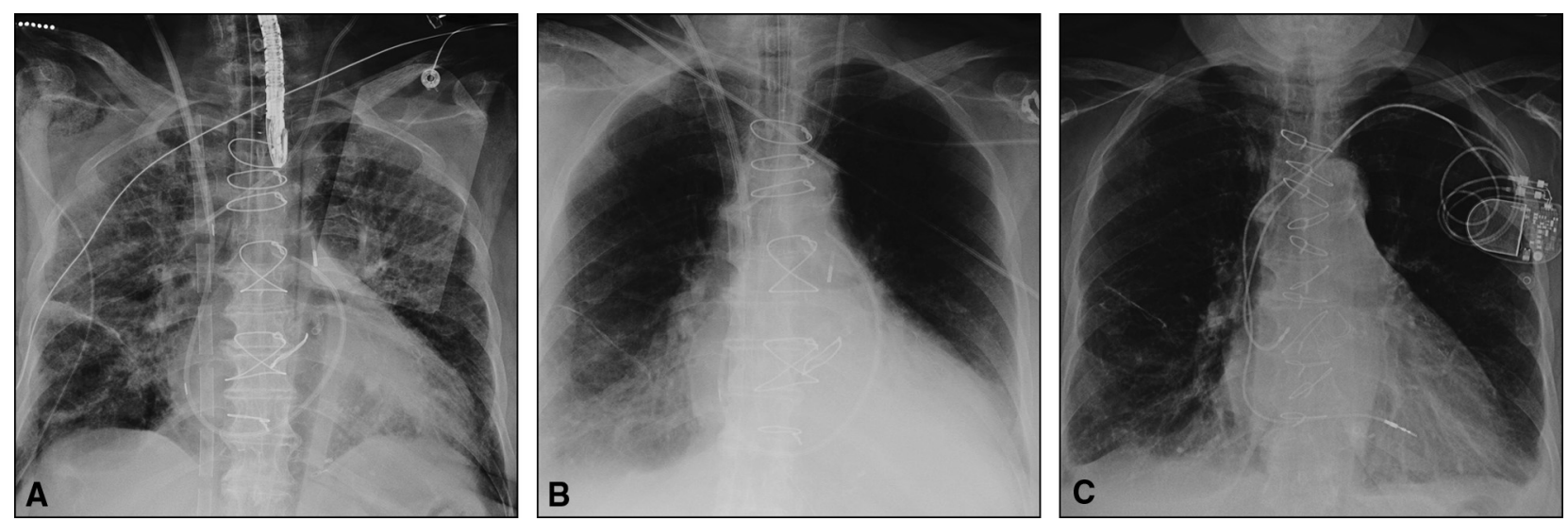

FIGURE 1. A, Chest radiograph after extracorporeal membrane oxygenation institution. B, Resolving pulmonary edema on extracorporeal membrane oxygenation support can be seen on the chest radiograph before aortic valve replacement. C, Chest radiograph before discharge from the hospital.

\section{References}

1. Hutter AM Jr, De Sanctis RW, Nathan MJ, Buckley MJ, Mundth ED, Daggett WM, et al. Aortic valve surgery as an emergency procedure. Circulation. 1970;41:623-7.

2. O'Brien SM, Shahian DM, Filardo G, Ferraris VA, Haan CK, Rich JB, et al. The Society of Thoracic Surgeons 2008 cardiac surgery risk models: part 2-isolated valve surgery. Ann Thorac Surg. 2009;88(1 Suppl):S23-42.
3. D’Ancona G, Pasic M, Buz S, Drews T, Dreysse S, Kukucka M, et al. Transapical transcatheter aortic valve replacement in patients with cardiogenic shock. Interact Cardiovasc Thorac Surg. 2012;14:426-30

4. Buchwald AB, Meyer T, Scholz K, Schorn B, Unterberg C. Efficacy of balloon valvuloplasty in patients with critical aortic stenosis and cardiogenic shock-the role of shock duration. Clin Cardiol. 2001;24:214-8.

\title{
Quantitative analysis of 3-dimensional aortic annular geometry: Implication for aortic root reimplantation
}

\author{
Liam P. Ryan, MD, ${ }^{\mathrm{a}}$ Melissa M. Levack, MD, ${ }^{\mathrm{b}}$ Joseph H. Gorman III, MD, ${ }^{\mathrm{b}}$ Robert C. Gorman, MD, \\ Rita C. Milewski, MD, PhD ${ }^{\mathrm{c}}$ and Joseph E. Bavaria, MD, ${ }^{\mathrm{c}}$ Charlotte, NC, and Philadelphia, Pa
}

The aortic valve reimplantation technique described and popularized by David and associates ${ }^{1}$ has demonstrated consistently excellent long-term outcomes during the past 2 decades in patients with aortic root dilatation but structurally normal, trileaflet aortic valves. The success of this operation, originally conceived as an alternative to aortic root replacement in patients with Marfan syndrome, has encouraged the broader application of derivative techniques to a number of distinct clinical scenarios, including bicuspid

\footnotetext{
From the Division of Cardiovascular Surgery, ${ }^{\text {a }}$ Sanger Heart and Vascular Institute, Carolinas Medical Center, Charlotte, NC; the Gorman Cardiovascular Research Group, ${ }^{\mathrm{b}}$ University of Pennsylvania School of Medicine, Philadelphia, Pa; and the Division of Cardiovascular Surgery, ${ }^{\mathrm{c}}$ University of Pennsylvania School of Medicine, Philadelphia, Pa.

Disclosures: Authors have nothing to disclose with regard to commercial support. Received for publication Dec 7, 2012; revisions received March 6, 2013; accepted for publication March 15, 2013; available ahead of print Dec 11, 2013.

Address for reprints: Joseph E. Bavaria, MD, Division of Cardiovascular Surgery, University of Pennsylvania School of Medicine, 3400 Spruce St, 6 Silverstein Pavilion, Philadelphia, PA 19104 (E-mail: Joseph.Bavaria@uphs.upenn.ed).

J Thorac Cardiovasc Surg 2014;147:1103-5 0022-5223/\$36.00

Copyright (C) 2014 Published by Elsevier Inc. on behalf of The American Association for Thoracic Surgery

http://dx.doi.org/10.1016/j.jtcvs.2013.03.046
}

aortic valve (BAV) syndrome with root dilatation and aortic insufficiency. ${ }^{2}$ Transposition of these valve-sparing techniques, all of which depend on restoration of functionally normal annular and leaflet geometry, to this geometrically unique patient population requires a thorough understanding of normal 3-dimensional BAV root complex geometry. ${ }^{3}$ To date, our collective understanding of root geometry in this patient population has largely been limited to 2-dimensional and anecdotal descriptors, which vary markedly among clinicians and institutions. ${ }^{4,5}$ In this study, we describe the rotational orientation of the aortic valve commissures in a cohort of patients with BAV without evidence of adverse remodeling. Our findings, which describe BAV root asymmetry in quantitative terms for the first time, have substantial implications for the ongoing evolution of valvesparing operative techniques in this patient population.

\section{MATERIALS AND METHODS}

Real time 3-dimensional echocardiographic data sets were acquired on 8 normal patients (tricuspid $\mathrm{n}=4$ and BAV $\mathrm{n}=4$ ) with an $\mathrm{iE}-33$ platform (Philips Medical Systems, Andover, Mass) equipped with a 2- to 7-MHz X7-2t transesophageal echocardiography matrix-array transducer. Inclusion criteria for both groups comprised maximum root diameter less than 